\title{
Sociologia de l'engany i de l'autoengany
}

\author{
Salvador Cardús \\ U nivsersitat Autònoma de Barcelona. D epartament de Sociologia \\ 08193 Bellaterra (Barcelona). Spain \\ salvador.cardus@uab.es
}

Resum

El principal problema de la sociologia és l'excés d'informació amb què s'ha de tractar, no pas l'escassetat. Així, doncs, les epistemologies adequades a l'escassetat d'informació tals com la indiciària, proposada per C arlo G inzburg, no resolen els problemes suscitats per la sociologia. En la seva exposició, l'autor proposa una epistemologia de la paradoxa que permeti donar resposta a l'anàlisi sociològica de l'engany i l'autoengany, del món que es dóna per descomptat, a l'evidència i a la confusió, a la confiança i el recel, a la memòria i l'oblit, a l'humor, a les passions i als sentiments.

Abstract. The sociology of deception and self-deception

The main problem of sociology is excess of information, no scarcity. Epistemologies must face scarcity of information. The epistemology of the trail by Carlo G inzburg, does not resolve the major questions set by sociology. The author's proposal is an epistemology of paradox for to face up the sociological analysis of deception and self-deception, the taken for granted world, evidence of confusion, confidence and suspition, memory and oblivion, humour, passions and feelings.

D e l'epistemologia indiciària a la paradoxal

\section{Carlo Ginzburg, Giovanni M orelli, Conan D oyle i Sigmund Freud}

Potser ja fa ben bé divuit anys, en el marc de l'assignatura d'Epistemologia - que llavors s'anomenava Lògica de la Investigació Científica- , vam desenvolupar un seminari paral·lel a propòsit d'una coincidència, potser d'una afinitat electiva, entre al guns alumnes - entre els quals hi havia en Josep Verdaguer i en Toni Estradé- i jo mateix, per a les novel-les policíaques de G. K. Chesterton que protagonitzava el capellanet catòlic, el PareB rown. A més, una altra 
coincidència en el temps, la presentació del Ilibre de C arlo Ginzburg El queso y los gusanos, a la qual havia assistit en Toni Estradé, ens permeté descobrir una versió del text reescrit diverses vegades d'aquest autor: Pistes. Arrels d'un para digma indiciari, que ens dibuixava tot un llarg camí que portava fins davant mateix d'allò que ens interessava.

Efectivament, tot i l'interès que tenia la proposta d'un paradigma indicia ri, les limitacions que presentava quan s'aplicava a la sociologia, ens semblava que quedaven en part resoltes si hi afegíem una nova dimensió: la de la paradoxa. És cert que el paradigma indiciaril resultava d'un gran interès a l'hora d'estudiar, precisament, els aspectes poc visibles de la realitat analitzada, però també ho era com a estratègia per a la descoberta d'allò que es pretén amagar 0 , encara, d'allò que és fora de la consciència de l'actor. D es de la tradició de coneixement pròpia dels pobles caçadors, guiats per les pistes que deixen les preses, fins a arribar a l'anàlisi de l'obra d'art tal com la proposava Giovanni M orelli, des del model implícit de descoberta que desenvolupa Conan D oyle en les seves novel-les protagonitzades per Sherlok H olmes i fins a l'epistemologia indiciària d'un Sigmund Freud (els actes fallits, els lapsus, els somnis... entesos com a pistes d'una realitat amagada) - autors entre els quals es pot establir, d'altra banda, una interessantíssima relació- , hi ha un fil que saparta d'una certa concepció del coneixement científic, de la noció de rigor i de la idea d'objectivitat que s'ha mantingut des de $\mathrm{G}$ alileu fins ara mateix.

\section{De Sherlock H olmesal Pare Brown}

El problema que resol aquesta epistemologia indiciària, dit telegràficament, és el com estudiar els fenòmens la força dels quals rau precisament en la seva invisibilitat. Una invisibilitat que es pot donar per tres raons diferents: per una objectiva manca de dades i documents - el cas de la història d'èpoques anti gues o de cultures o grups socials sense tradició escrita - ; pel fet queles dades disponibles poden ser el resultat d'una estratègia emmascaradora i, per tant, d'engany - com seria, actualment, la informació periodística o fins i tot moltes dades obtingudes a través de sondejos d'opinió- , i, finalment, perquè l'absència de dades pot formar part de la mateixa condició de funcionament de determinades xarxes de relació, d'estructures de poder i de sistemes de significació públiques i privades. Perquè el cert és que bona part de la realitat social és d'aquest tipus 0 , encara més ben dit, no hi ha cap àmbit social que no contingui elements d'aquesta naturalesa «invisible» que, a més, solen ser de molta rellevància.

M és particularment, el problema que planteja la perspectiva sociològica de manera més accentuada que altres ciències socials és que, generalment, el seu

1. C arlo Ginzburg. «Señales. Raíces de un paradigmaindicario», a Crisisdela razón de Aldo Gar gani, ed. M éxico, Siglo XXI editores, 1983. A més, podeu veure el número 26 de la revista Papers, Conexxement, Indicisi paradoxes (1986), amb articles de J.M. Terricabras, Antoni Estradé, J oan Estruch i Salvador Cardús. 
principal adversari és l'abundància d'informació, l'excés, que fa molt difícil poder-la convertir en dada científica, i això quan aquesta informació no busca, com hem dit, no només confondre, sinó enganyar astutament. És per això que si a més treballem en una perspectiva sociològica que troba la seva força analítica - i també pràctica - en el fet de partir, d'entrada, més d'una voluntat de comprensió que no pas de la de judici o actuació, el model epistemològic que, literàriament, proposa $C$ hesterton amb el seu Pare Brown, el de la descoberta per la paradoxa, ens resultava - intuïtivament- d'una gran potència. I no devíem anar tan mal encaminats quan, anys més tard, en Toni Estradé trobava en una de les cartes de G ramsci des de la presó, una reflexió en aquest sentit en la comparació entreel model de coneixement de H olmes i de Brown.

\section{La construcció de la intersubjectivitat}

Tot i que tinc la impressió que mai no hem acabat d'explotar prou a fons aquella intuïció només desenvolupada sistemàticament en un número de la revista PAPERS, el cert és que en aquest pla intuïtiu, el model ha governat molt profundament els treballs de recerca dels membres de l'Isor i d'altres companys. Unes intuïcions que porten a, primerament, desconfiar del'evidència; després, a parar atenció als petits elements aparentment irrellevants; però, sobretot, a estar atents als dobles significats de determinades accions que, més enllà de la seva significació explícita, poden estar anunciant el contrari d'allò que insinuen o mostren explícitament. D 'altra banda, tot i que en els nostres treballs no ens hem limitat a l'anàlisi de la intersubjectivitat, en canvi, es pot dir que mai no hem desatès el paper central que aquesta dimensió té en qual sevol fet social, i en especial en l'anàlisi dela religió i de la cultura. Per nosal tres, potser sense tota la disciplina i el rigor que serien exigibles, el paper del'engany i l'autoengany, de l'evidència col lectiva i de la confusió, del món donat per descomptat i del sentit comú, de la il|lusió i la desil·lusió, de la confiança i el recel, de la memòria i l'oblit, i fins i tot del'humor, de la passió o dels sentiments, han estat molt presents en els nostres treballs.

És clar que la majoria d'aquests conceptes ja són presents en l'obra de P.L. Berger, que ha marcat decisivament la nostra trajectòria. Ell mateix ens ha reconegut com la seva secta a Barcelona, i això pot explicar que, gai rebé simultàniament, shagi publicat l'original anglès i la versió catalana de la seva darrera obra, La rialla que salva, traduïda per Joan Estruch i que inaugura la col·lecció que dirigeixo per a La C ampana. Però també és en la línia d'altres autors, com Randall Collins (Sociol ogical Insight, 1982), que, amb tota pre cisió, ha caracteritzat la sociologia com a ciència de la no-obvietat, i que l'ha definit com I'anàlisi dels fonaments no racionals de la racionalitat social. 0 , més recentment, I'hem trobada en aproximacions relatades amb bellesa, passió i agosarament per Ann Gamei Andrew M etcalfe a Passionate Sociology (1996). 